\title{
EL DISCURSO PATRIARCAL EN LA POESÍA FEMENINA DEL PRIMER FRANQUISMO
}

\section{PATRIARCHAL DISCOURSE IN SPANISH WOMEN'S POETRY DURING FRANCO'S REGIME}

\author{
José JURADO MORALES
}

Universidad de Cádiz

jose.jurado@uca.es

Resumen: Este artículo trata de mostrar cómo la poesía de autoría femenina de los primeros lustros del franquismo se hace eco del poder patriarcal defendido por el nacionalcatolicismo. Para ello y a modo de ejemplo, se citan a algunas poetas que reflejan este contexto sociológico en sus poemas mediante la presencia de un sujeto poético femenino que responde a unos estereotipos sociales y el tratamiento de unos mismos temas que atañen a la sumisión amorosa, la maternidad, la familia, la infancia, la relación con los hijos y otros motivos limítrofes.

Abstract: The aim of this paper is to show how women's poetry in the early years of Franco's regime echoes the patriarchal power defended by NationalCatholicism. I shall study some poets who reflect this sociological context in their poems through the presence of a female poetic subject that responds to social stereotypes and the treatment of some issues such as loving submission, motherhood, family, childhood, relationships with children, etc. 
Palabras clave: Poesía femenina española de posguerra. Nacional-catolicismo. Discurso patriarcal.

Key words: Postwar Spanish women's poetry. National-Catholicism. Patriarchal discourse.

La historiografía literaria ha perpetuado un ramillete de cinco o seis mujeres poetas adscritas a la primera generación de posguerra y ha soslayado el nombre de otras muchas que dieron a conocer poemarios o poemas en publicaciones periódicas y que apenas si se las recuerda. La exclusión de una historia de la literatura dominada por hombres, la poca calidad de sus producciones, la vetustez de los temas y los estilos empleados, el abandono de sus carreras apenas comenzadas o la comunión con los preceptos franquistas, entre otras razones, pudieran explicar el olvido que hoy padecen. Sirva la referencia a la selección que prepara José Luis Martínez Redondo en 1953 bajo el título de Poesía femenina (Antología) para constatar el desconocimiento que en la actualidad adolecen las antologadas: María Dolores Alegre, Maruja Collados, Inma de Espona, Carmen Martínez Santolaya, María del Carmen Pescador, Luz Pozo Garza, Josefina Sánchez Pemán, María Dolores Tello y Guillermina Vives. Más conocidas resultan hoy día las que incluye Carmen Conde en Poesía femenina española viviente en 1954, compilación reeditada en 1967 con el título de Poesía femenina española (1939-1950), aunque también se dan cita algunas olvidadas entre las veintiséis: María Alfaro, Ester de Andreis, María Beneyto, Ana Inés Bonnín, Carmen Conde, Mercedes Chamorro, Ernestina de Champourcin, Beatriz Domínguez, Ángela Figuera, Gloria Fuertes, Angelina Gatell, Clemencia Laborda, Chona Madera, Susana March, Trina Mercader, Pino Ojeda, Pilar Paz Pasamar, Luz Pozo Garza, Josefina Romo Arregui, Alfonsa de la Torre, Josefina de la Torre, Montserrat Vayreda, Pilar Vázquez Cuesta, Pura Vázquez, Celia Viñas y Concha Zardoya ${ }^{1}$. Si bien hoy apenas se recuerda a muchas de ellas, toca reconocer, al margen de sus respectivos méritos artísticos, su presencia en periódicos, revistas, antologías y libros de la época como prueba de que, entonces al menos, tuvieron cierta repercusión entre los lectores.

En las páginas que siguen me centraré en la órbita de la mujer de posguerra para intentar exponer cómo la lectura de algunos de sus poemas

${ }^{1}$ En las referencias que hago en el presente artículo a poemas recogidos por Carmen Conde (1967) sigo la edición de Poesía femenina española (1939-1950). De casi todas las citadas da buena cuenta María Payeras (2009) en su monografía Espejos de palabra. 
constata la presencia de un sujeto poético femenino que, mediante la recreación de unos estereotipos sociales supeditados a la relación de aquella con el hombre, da cuenta del patrón nacional-católico de mujer que se pretende imponer. Son poemas que atienden en último término a las demarcaciones del hogar y reiteran unos mismos temas que atañen a la sumisión amorosa, la maternidad, la familia, la infancia, la relación con los hijos y otros motivos limítrofes. La mención de los asuntos tratados ya valida una primera conclusión sobre la construcción oficial de la personalidad femenina: la mujer teje su identidad en función de los otros, especialmente de los varones de la casa (padre, marido, hijo), es decir, edifica su identidad a partir de la alteridad, no de la mismidad, lo que puede repercutir en un estado de frustración y un sentimiento de irrealización vital.

Para arropar en su contexto esos poemas, me fijaré en declaraciones y textos del momento que funcionaron como plataformas de adoctrinamiento para el perfecto encaje social del hombre y la mujer comunes, los individuos de la calle en su día a día, con unas funciones y rasgos intachablemente delimitados. Las jerarquías políticas y eclesiásticas, en donde germinan muchas de las manifestaciones dogmáticas que citaré, desean perpetuar su poder patriarcal mediante la disposición de un modelo de identidad femenina falazmente asociado a un orden natural o a un mandato divino y, por ende, incuestionable.

\section{DULCE COMPANERA, AMANTE ESPOSA Y MADRE ABNEGADA}

En tal entorno la mejor carta de presentación de toda mujer — por lo menos, la de la mujer corriente, el ama de casa tradicional — consiste en hacer gala de la servidumbre, considerada propia de su género, y mantenerse alejada de cualquier participación social. Esto significa que la mujer se convierte en elemento adjetivo del hombre, al que debe rendir obediencia ciega y al que debe consagrar el don de la maternidad. Por tanto, hay en el franquismo una pérdida de las conquistas republicanas y una vuelta a un sistema reaccionario en el que la mujer ha de guiarse por la sumisión y la reclusión en el hogar y el hombre por ser el pater-familias que ostenta el poder económico y moral y, en consecuencia, la voz y el mando de los suyos. Esta síntesis, sim- 
plista quizás, pero reveladora de un espíritu de época, puede valer de adelanto de lo que trataré de argumentar en páginas venideras ${ }^{2}$.

Hay muchas circunstancias históricas decisivas para comprender esa nueva identidad de lo femenino abrigada por la oficialidad franquista o, lo que es prácticamente lo mismo, para atisbar la distancia que separa la situación de la mujer en la posguerra de la que pudiera haber alcanzado si la guerra no hubiese truncado los logros de la república. Uno de los hechos más tempranos apunta al 23 de setiembre de 1936, fecha del decreto que prohíbe la coeducación en España y que supone el inicio de una formación basada en la desigualdad. Claro que un decreto no explica por sí solo los parámetros sociológicos del momento en su conjunto, ni puede sostenerlos en el tiempo. Esta situación se instaura con tanta fuerza en el primer franquismo porque los dos discursos sobre los que este se asienta, el católico y el falangista, convergen en la idea de la superioridad masculina y en la apología de la maternidad como verdadero sentido en la vida de las mujeres, es decir, convergen en considerar a la mujer no en su individualidad sino en su condición de complemento como esposa y madre. La Iglesia Católica se muestra tajante al respecto y no hay más que acudir a algunas declaraciones de la época, como la que sigue del padre Delgado Capeans ${ }^{3}$, para hacernos una idea de su discurso conservador:

[E]l feminismo moderno no se contenta con los triunfos y conquistas realizados por el Evangelio. Quiere algo más, aspira a nuevas conquistas. No se contenta con ser la dulce compañera del hombre, la amante esposa y la madre abnegada; quiere emanciparse de él, aspira a contar con sus propias fuerzas, a poder vivir por sí sola, sin el auxilio del hombre; quiere la conquista de la perfecta igualdad entre ambos sexos en todos los cargos y manifestaciones públicas; la instrucción integral. ... Esto y otras muchas más conquistas quiere el feminismo moderno para la mujer de hoy, aun a trueque de dejar en el camino, hecho jirones, el tesoro más hermoso de la mujer: su feminidad (Molinero, 1999: 69).

${ }^{2}$ Este mundo sociológico queda explicado de forma detallada y amena en los Usos amorosos de la posguerra española que Carmen Martín Gaite (1987a) escribiera en los años ochenta, donde pueden encontrarse mil y un ejemplos de las relaciones entre el hombre y la mujer en la década de los años cuarenta. También acarrea un buen número de citas muy clarificadoras del papel que la mujer ha de desempeñar el artículo «El uso de la palabra misión en el lenguaje de la prensa femenina española (1939-1945)» de Pilar de Vega Martínez (1988).

3 Un buen repertorio de las conferencias sobre el asunto pronunciadas por Ricardo Delgado Capeans (1941) está recogido en su libro La mujer en la vida moderna. 
Este radicalismo se acrecienta si cabe en los estatutos y discursos de la Sección Femenina de Falange en los que se insiste una y otra vez en la subordinación y la inferioridad de la mujer con respecto al hombre como misión encomendada por la Patria. Los ejemplos resultan múltiples y muchos son conocidos, pero merece la pena traer a colación algunas manifestaciones de Pilar Primo de Rivera entresacadas de sus arengas: «[las mujeres tienen una] misión de ayuda, no es misión directora, porque esa solo corresponde a los hombres» (Zamora, III Consejo Nacional, 1939); «Las Secciones Femeninas respecto a sus Jefes tienen que tener una actitud de obediencia y subordinación absoluta. Como es siempre el papel de la mujer en la vida, de sumisión al hombre» (Barcelona, V Consejo Nacional, 1941); «Las mujeres nunca descubren nada; les falta, desde luego, el talento creador, reservado por Dios para inteligencias varoniles; nosotras no podemos hacer nada más que interpretar mejor o peor lo que los hombres nos dan hecho» (I Consejo Nacional del Servicio Español del Magisterio, 1943). En fin, en una entrevista aparecida en Pueblo, en mayo de 1948, a la pregunta sobre cuáles son los objetivos primordiales de la educación de la mujer responde que «como siempre, porque para eso no hay edades, los de prepararla para que sepan crear y dar fundamento a una nueva familia donde, en medio de una apacible y amorosa convivencia, se llena la vida de un profundo sentimiento religioso y se aprende a servir a la Patria» (Molinero, 1999: 71-72, 78).

El modelo femenino defendido por la Iglesia y la Sección Femenina de Falange se inculca en la mujer a través de los resortes del poder: a las niñas y adolescentes en las escuelas, a las jóvenes durante el Servicio Social, y a estas y a las adultas a través de los medios de comunicación (radio, periódicos y revistas) con los consultorios sentimentales, las entrevistas, las charlas religiosas, las cartas al director, los artículos de las firmas invitadas, las radionovelas, etc. En este sentido, las revistas de la Sección Femenina - Medina, $Y$, El Ventanal - se erigen en vehículos perfectos para difundir entre las amas de casa la necesidad de atender el hogar, al marido y los hijos. En un plano literario, también se aprovechan estas revistas para promover un tipo determinado de literatura entre las escritoras, muy numerosas en la época, pero invisibles por su alejamiento de las grandes editoriales, los premios, los jurados, las antologías y las instituciones. Muestra de ello son las entrevistas realizadas a escritoras afectas al régimen (Carmen Martín de la Escalera, María José Pomar, Blanca Espinar, etc.) o la sección titulada «¿Servirías tú para escritora?», inaugurada en 1947, en El Ventanal, en la que se aconseja cómo escribir y qué leer, con una predilección por el género rosa, el componente autobiográfico y un estilo dotado de sencillez y gracia 
(Zecchi, 2002). A buen seguro, iniciativas como esta debieron influir en muchas de esas escritoras que terminan por acatar y difundir el patrón femenino social del franquismo. El caso de algunas novelistas constituye un buen ejemplo, ya que autoras como Carmen de Icaza, Eugenia Serrano, Concha Linares Becerra o Concha Suárez de Otero asumen el género de la novela rosa como propio de la mujer y construyen, con todas las variantes que se quiera, un tipo de heroína definida por la sensibilidad, la abnegación, la resignación, la entrega y el cariño frente a unos hombres fogosos, valientes, aventureros e inteligentes (Montejo, 2006).

\section{YO TE BENDIGO: LOS POEMAS IMPERIALISTAS}

Tampoco la poesía escrita por mujeres en los años cuarenta escapa al modelo de sociedad patriarcal apuntado. Hoy día se conoce mucho mejor a aquellas autoras que disienten notablemente de este discurso, como Ángela Figuera, Gloria Fuertes, Carmen Conde, Concha Zardoya y otras más jóvenes o menos famosas que componen buenos testimonios de una poesía que bascula de lo existencialista a lo social con un claro compromiso contra la dictadura. No obstante, existen otras muchas poetas que han pasado con menos gloria a la posteridad por razones de calidad literaria o de fundamento ideológico, pero cuyas obras almidonadas en el tiempo han quedado como un documento valioso para examinar hoy día las señas de identidad propiciadas por el ideario franquista para la mujer.

Como paradigma del influjo que ejerce el totalitarismo en la poesía femenina de la primera posguerra, habría que señalar aquellos poemas en los que las escritoras celebran la victoria del bando nacional en la guerra y alaban la persona y las hazañas bélicas de los héroes y mártires en un sentido similar al registrado en las varias compilaciones de signo bélico estampadas entre 1939 y $1941^{4}$. La aportación femenina más relevante en este terreno quizás corresponda a la gallega Pilar Millán Astray, hermana del fundador de la Legión y conocida sobre todo por su labor de dramaturga con éxitos como La tonta del bote. Las vivencias de su paso por las cárceles de Murcia

\footnotetext{
4 Los títulos más nombrados son: Romances de la Cruzada de Rafael Balbín, Altura de José M. ${ }^{\mathrm{a}}$ Castroviejo, Poesía legionaria de José Antonio Cortázar, Romances y episodios de la Revolución roja de Félix Cuquerella, Romances de la Falange de Rafael Duyós, Romancero tradicional de Ernesto La Orden, Romancero legionario y Calendario poético de la Cruzada de Antonio Maciá Serrano, Poemas de guerra de Alfredo Olavarría, Lira bélica de José Sanz Díaz, Antología poética del Alzamiento de Jorge Villén y la Corona de sonetos en honor de José Antonio.
} 
y Alicante durante la guerra civil nutren los poemas recogidos en Cautivas. 32 meses en las prisiones rojas de 1940. Se trata de un poemario en la línea política de los referidos en esas compilaciones, que titula precisamente «Al Caudillo» y que se abre con el siguiente soneto:

General y Señor: Yo te bendigo;

Yo, admirando tu bélica aureola, siento vibrar mi sangre de manola;

y entusiasmada tus victorias sigo.

El triunfo nos dará tu pecho amigo

y del marxismo barrerás la ola.

No olvides, Franco, que nací española,

y es la pura verdad cuanto yo digo.

En tu lucha gigante te acompaña

el corazón de la mujer de España;

y cuando triunfes, $y$ tras mil dolores,

pase tu nombre al libro de la Historia, ino habrá en España suficientes flores, oh invicto General, para tu gloria! (Millán Astray, 1940: 15).

El soneto tiene bastante enjundia y podría repararse en algunos lugares comunes en la poesía imperialista de entonces, entre ellos, la apología del patriotismo — «nací española»—y de la exterminación del enemigo — «del marxismo barrerás la ola»—. No obstante, lo que ahora me interesa resaltar desde la perspectiva de una poesía femenina partidaria del régimen naciente radica en que de algún modo la escritora gallega poetiza el espíritu de la Sección Femenina de Falange, que recoge en el preámbulo de sus estatutos, aprobados en 1937, que esta Sección nace porque «aquel movimiento arriesgado, varonil y difícil, necesitaba, precisamente por su fortaleza, el más fino complemento de la labor femenina para asistir y aliviar las derivaciones de sufrimiento que la conducta heroica de la Falange ocasionaba». Es decir, Pilar Millán Astray asume las señas de identidad franquistas relativas a la subordinación de la mujer al hombre en la causa nacional — «te acompaña / el corazón de la mujer de España» (Mullor-Heymann, 1998: 87-88)-. Al mismo tiempo, hay otro aspecto muy significativo: la glorificación casi religiosa de la figura de Franco. Más allá de la alabanza en sí, esto supone que la escritora aproxima las figuras de Franco y Dios, este como padre de los cristianos y aquel como padre de los españoles, algo inteligible desde el 
instante en que advertimos la vinculación de este paralelismo con la hegemonía patriarcal de la dictadura que enaltece la tríada paternalista formada por Dios, el Caudillo y el marido, este último a su vez como padre de los futuros súbditos. En suma, los versos de Millán Astray no solo exaltan la imagen militar de Franco, sino que en la base proyectan una concepción del mundo en la que la mujer se encuentra totalmente supeditada al hombre, entendido como un ser superior capaz de tales hazañas bélicas y otras más mundanas.

Este soneto de Millán Astray constituye un caso extremo de clara adscripción política muy vinculado todavía a los fragores militares de la guerra y las loas a los héroes nacionalistas. A medida que el 1 de abril de 1939 se va distanciando en el tiempo, en los textos (poéticos, narrativos, dramáticos y periodísticos) de las escritoras profranquistas se atenúa la inclinación imperialista, pero no desaparece la consignación de ese estatus sociológico antes aludido orientado por la Falange y la Iglesia mediante el enaltecimiento de los valores nacional-católicos.

\section{CUANTO MÁS FECUNDAS, MÁS MADRES: LOS POEMAS DE LA MATERNIDAD}

Haciéndose eco de las palabras de Pío XI en la encíclica Casti Connubii del 31 de diciembre de 1930 y de otros muchos discursos de Pío XII, los principios del nacional-catolicismo defienden la procreación como fin de todo matrimonio. Así se difunde en la literatura edificante de posguerra y se escucha en programas radiofónicos como las Charlas de orientación religiosa, del padre Venancio Marcos, emitidas desde 1944 o las Lecciones de Buen Amor, un curso de educación prematrimonial del padre Ángel Villalba desde 1954. En el número 44 de $Y$, la revista de las mujeres nacionales sindicalistas, leemos a la altura de setiembre de 1941 un texto titulado «Carreras para la mujer», en el que se lee: «La verdadera carrera de la mujer es la de madre de familia. Estamos de acuerdo que es a la que deben todas aspirar, exceptuando un escaso número que otras vocaciones más sublimes puedan acaparar» (Vega Martínez, 1988: 138). El padre García Figar (1945a) lo tiene bastante claro: «¿Para qué me caso? La naturaleza contesta que la unión del hombre con la mujer responde a un grito de la especie, que quiere sobrevivirse y perpetuarse en el mundo hasta tanto llegue el cataclismo final. ¡Los hijos!». En términos del abad Carlos Grimaud (1942: 344): «Ella ha sido hecha moral, intelectual y corporalmente para ser madre; de ahí proviene toda su dignidad». Pío XII sostiene que 
«Dios ha dado a la mujer la misión sagrada y dolorosa, pero fuente a la vez de purísima alegría, de la maternidad, y a la madre está confiada, antes que a nadie, la primera educación del niño en los primeros meses y años» (Acción Católica Española, 1955: 977; Vega Martínez, 1988: 124). En fin, el cardenal Gomá (1946: 194) anima a la familia numerosa con su «cuanto más fecundas, más madres».

Esta política garante de la natalidad construye un cuadro social en el que la mujer siente la necesidad y la obligación de tener un hijo, pues la maternidad se transmuta en su deseo primero y su aspiración última por aquiescencia personal como forma de alcanzar la realización individual y por presión externa como fórmula para ayudar a la construcción de la Patria. En este contexto toda mujer que no sea madre contraviene la misión encomendada por mandato divino y disposición gubernamental y sufre cierto rechazo, hasta el grado de que el mismo Pío XII llega a considerar que «la esterilidad es con frecuencia el castigo del pecador» (Pío XII, 1951: 1757; Roca i Girona, 1996: 230).

La genovesa Ester de Andreis, afincada en Barcelona a los cinco años, publica el poemario Prímula en 1943. Andreis, educada a caballo entre España, Italia e Inglaterra, traductora de Katherine Mansfield, Louise Labé y Elizabeth Barrett Browning, anfitriona de tertulias y encuentros poéticos en su casa barcelonesa del número 55 de la calle Ganduxer (Ridruejo, 1976: 271), tiene un poema titulado «El hijo que nunca tuve», publicado en Attimi (1946) y traducido en Instantes (1982), que manifiesta de forma ejemplar la carencia que el discurso dominante hace sentir a la mujer infecunda o estéril. Según el pensamiento hegemónico, la mujer se realiza al tener descendencia, de ahí que en el poema «El hijo que nunca tuve» (recogido en Conde, 1967: 47-48) afloren los sentimientos de nostalgia y soledad, el deseo soñado y no alcanzado de haber alumbrado a ese niño:

\author{
El hijo que no tuve nunca \\ desde siempre me aguarda \\ en la vida que no he vivido. \\ Se apresura a mi encuentro con sus ojos \\ limpidamente claros \\ absortos en el horizonte. \\ Se posa el aire abril en su rostro, \\ en su frente serena, \\ su cabello dorado. \\ Siempre sonríe el sol
}


en sus años y cantan

luminosos cantares

las veredas, los prados y los bosques

por los que él ha pasado.

Cuando nace la luna

se queda pensativo

y advierte que con él me pierdo

en la diáfana luz

y que vivo la vida que jamás he vivido.

El hijo que no tuve nunca sufre

la nostalgia de mi infinita ausencia

y repite palabras de amor, leves,

que no oyó todavía,

enjuga el llanto de mi voz

y se pierde en mi día solitario

a contemplar las horas

que jamás podrán ser. Me pide entonces

las caricias, los besos

que tan solo he soñado (Andreis, 1982: 51-52).

Al mismo respecto, la gironesa Montserrat Vayreda ${ }^{5}$, que no publica su primer libro, Entre el temps i l'eternitat, hasta 1955, cuando ya rebasa los treinta años de edad, escribe un poema titulado «Autoelegía de la mujer estéril» (Vayreda, 1954: 19; recogido en Conde, 1967: 362-363), en el que el sujeto poético femenino declara el dolor acumulado por su esterilidad a partir de la imagen del árbol sin fruto:

Mi cuerpo vibra, late, siente. Ansío

liberarle de aquello que desea;

él es el tronco que en su pleno estío

dice a la yedra: ; Que tu abrazo sea!

Yedra: tacto sin fin que se encarama

hasta la copa - mi mortal cabeza-

que encuentra en cada brazo tierna rama

poblada por cien ríos de tibieza.

Si de mis senos las pequeñas lomas

sienten de tales ríos la ternura

5 Para un primer acercamiento a su obra puede consultarse Poemes de Montserrat Vayreda (Antologia 1945-2004) en edición de Anna M. Velaz i Sicart (2005). 
vibran y laten como dos palomas

que encuentran en el árbol su postura.

Y la cintura erguida, afianzada

en la raíz vital que la alimenta

no se siente jamás arrebatada

por una mano audaz o violenta.

Siguen los pies clavados en la firme

tierra donde nací. Los pasos dados

se concentran en uno, en el de asirme

en el barro sin fin de mis pecados.

Árbol sin fruto soy, árbol herido

por las tormentas que en su centro estallan,

árbol que nunca ha cobijado un nido,

árbol con muchos labios que se callan.

Árbol apasionado por la vida

de los pájaros todos que la habitan

- sueños de una ternura presentida-

que amargan, que murmuran y que incitan.

Cuando me caiga al fin, si alguien advierte

todo el dolor que floreció en mis ramas,

verá también que luego de mi muerte

todo el amor se me levanta en llamas (Vayreda, 1954: 19).

En el supuesto de que esa criatura se conciba, la jerarquía familiar se consolida: el pater-familias busca el sustento económico en el espacio abierto de la calle y la mujer queda más confinada aún al hogar para encargarse de su crecimiento. Mientras son pequeños, la mujer rige en la casa y los hijos obedecen, con lo que, como madre y educadora, esta se sitúa en la pirámide social y familiar por debajo del hombre, pero por encima de los hijos. El problema surge cuando se trata de varones ya que, al crecer, pronto pasan a ser hombres y, en consecuencia, a adelantar a sus madres en el escalafón. La barcelonesa Susana March, esposa del novelista cántabro Ricardo Fernández de la Reguera, escribe en estos años Rutas (1938), Poemas de la Plaza Real (escrito entre 1939 y 1945, y publicado en 1987) y La pasión desvelada (1946), el de contenido más amoroso de los tres. Ya desde esta temprana producción se avista un tono existencialista, una dialéctica entre el deseo de rebelión y la resignación ante el destino y una reflexión sobre las restricciones impuestas a la mujer. Por ejemplo, en el poema «Dudas» de 
Rutas expresa su deseo de libertad frente al sometimiento a la vida vulgar6. Susana March incluye el poema «Mi hijo ha crecido este verano» en $\mathrm{La}$ tristeza ${ }^{7}$, accésit del Premio Adonais 1952, dedicado a su unigénito de nombre Alfredo, que revela a las claras algunas señas pertinentes ligadas a la sensación de inferioridad de que adolece la mujer:

Mi hijo ha crecido este verano.

Me pone las manos sobre los hombros y me dice:

«iMira, soy casi tan alto como tú!»

Se empina un poco todavía.

Pero pronto será tan alto como yo. ¡Y más alto!

Pronto seré yo la que tendré que empinarme para besarle en la mejilla.

Pronto ya no podré decirle esas cosas pueriles que dicen las madres a sus hijos:

llamarle «sol mío», hacer como que me sorprendo

por cualquier acto suyo,

arroparle por las noches

cuando ya esté dormido.

Pronto ya no podré contarle

esas historias que le gustan tanto,

las heroicas hazañas

que yo cometí cuando era joven, porque me diría:

"Si tú eres una mujer. Y las mujeres no cometen hazañas heroicas».

Y yo sentiré delante de sus ojos todo el triste rubor de mi sexo.

Ya no seré nunca más osada, ni grande, ni amiga

de pájaros emigrantes y marineros taciturnos.

Volveré a ser lo que siempre fui:

una mujer insatisfecha de ser mujer y de todo.

¡Porque el único en este mundo que me veía grande

habrá crecido más que yo! (March, 1957: 56).

Tras la aparente sencillez de la anécdota recogida —el crecimiento de un hijo-, el poema de Susana March deja constancia de algunos detalles aclaratorios de la relación hombre-mujer en la época. El temor de

${ }^{6}$ Cf. los varios trabajos de Susana Cavallo dedicados a Susana March, entre ellos el titulado «Polvo en la tierra: la poesía temprana de Susana March» (Cavallo, 2006).

7 Posteriormente lo reúne en Poemas. Antología (1938-1959). Recogido también en Carmen Conde (1967: 235). Susana March recopilaría los versos dedicados a su hijo Alfredo en Los poemas del hijo, en el que también incorpora un poemita dedicado a su nieta Tanit, escrito en la noche del nacimiento de esta. Agradezco esta información a Susana Cavallo, profesora en Loyola University Chicago y especialista en Susana March. 
la protagonista a la pérdida del influjo sobre su hijo y de la admiración que este le profesa — «el único en este mundo que me veía grande»descubre un máximo grado de conciencia de esa realidad por parte de la mujer. Su reflexión sobre el porvenir alcanza una alta cota de patetismo justamente por el hecho de que confiesa su angustia presente, su sinvivir actual por el recelo de un daño futuro. Sufre ya por lo que sabe que vendrá seguro. Y lo que vendrá es un hijo que se le plantará más temprano que tarde con un discurso patriarcal que restringe cualquier virtud y ningunea toda iniciativa femenina, incluso las más extraordinarias. Esta actitud, expuesta además en un contundente estilo directo en boca del hijo — «Si tú eres mujer. Y las mujeres / no cometen hazañas heroicas»-, comporta que la mujer sufra un estado de inferioridad que, para más afrenta, no encuentra la discrepancia de esa madre del poema, sino todo lo contrario: «Y yo sentiré delante de sus ojos / todo el triste rubor de mi sexo». La anécdota remata, pues, en una guisa de acatamiento de un orden establecido en función del sexo que relega a la mujer al empacho, el descontento, la pesadumbre, el pesimismo, la falta de fe en su condición femenina: «Volveré a ser lo que siempre fui: / una mujer insatisfecha de ser mujer y de todo». O sea, ni tan siquiera la maternidad logra una realización gratificante como se infiere en los versos finales en los que claramente hay una resignación al devenir de las relaciones madre-hijo. En cierto modo, esto no es más que una variante del mito de la mater-dolorosa, $\tan$ vociferado en el franquismo con la vinculación de la figura de la mujer-madre a la Virgen María y que en última instancia remite al pasaje del Génesis que suscribe «Parirás con dolor los hijos» (Génesis, 3: 16). Un editorial, del 10 de abril de 1941, de Medina, el semanario de la Sección Femenina de Falange, rubrica: «Y así, la mujer, en el recuerdo del humano dolor de la Virgen María, sabe también su misión abnegada, sencilla, heroica» (Vega Martínez, 1988: 137). En conclusión, el sujeto poético propuesto por Susana March acaba asumiendo esa filosofía del sufrimiento y de la resistencia ante las adversidades propia del nacionalcatolicismo y que, en el ámbito femenino, culmina con la entrega a los hijos. En un artículo de octubre de 1941 titulado «La misión de la mujer» y aparecido en el número 47 de la revista La Mujer de Acción Católica (Pastor, 1984: 34) se lee que «la mujer que es madre se olvida de sí misma para no pensar más que en los demás». José Juanes lo expresa así: «El gozo de ser madre por el dolor y el sacrificio es tarea inexcusable femenina que da gloria después, cuando en el más allá se sopesen martirios y merecimientos»(Juanes, 1942; Vega Martínez, 1988: 137). 


\section{EN LA SOMBRA, EN LA MODESTIA Y EN LA SUMISIÓN: LOS POEMAS AMOROSOS}

Son tiempos de menguas y abnegaciones y en esta coyuntura la invocación al espíritu de sacrificio por los demás se extrema en el contorno de la mujer en su condición de esposa, pues la entrega a los seres queridos ha de tornarse en obediencia ciega y sumisión al pater-familias, un equivalente en el hogar al héroe militar en el campo de batalla al que hay que rendir pleitesía. La Iglesia del franquismo hace suya la figura del cabeza de familia que tantas deudas cristianas tiene: ya en el Génesis la mujer aparece subordinada al hombre como ser nacido de él y en la epístola de San Pablo a los Efesios (5: 22-24) se dice que «las casadas estén sujetas a sus maridos como al Señor; porque el marido es cabeza de la mujer, como Cristo es cabeza de la Iglesia, y salvador de su cuerpo. Y como la Iglesia está sujeta a Cristo, así las mujeres a su maridos en todo». En fin, la máxima del artículo 57 del código civil de 1944 reza que «el marido debe proteger a la mujer y esta obedecer al marido». La declaración de Carmen Werner, responsable de las secciones femeninas del Frente de Juventudes, relativa a la regulación falangista tiene extensión a la organización familiar:

O sea, que la Sección Femenina, que es un conjunto de mujeres, no debe desnaturalizarse ni cambiar su condición, sino que para ser eficaz o para ser colaboradora en la obra viril de la Falange tendrá que mantenerse en la sombra, en la modestia y en la sumisión, y con ese complejo, y envueltas en las usuales formas femeninas de gracia y amabilidad, entablar vuestras relaciones con las Jerarquías (hombres) (Molinero, 1999: 73-74).

Ciertamente cualquier pesquisa de testimonios al respecto se antoja infinita: «Y, al crearla. Dios le asigna [a la mujer] un papel ilimitado de ayuda para el hombre» (Fuertes, 1944; Vega Martínez, 1988: 135); «Y tiene [la mujer] su «emulación» principal en la forja de hombres, que a su cuidado y solicitud están encomendados. Esta obra es superior a la construcción de catedrales y castillos» (García Figar, 1945b; Vega Martínez, 1988: 136); «la mujer debe ser instruida, no para sobreponerse a su marido, sino para mantenerse a su lado con dignidad; cultivada, no con orgullo insolente y seco, sino con la dulzura de una abnegación modesta» («La mujer y el hogar», 1938: 15; Pastor, 1984: 35).

La valenciana María Beneyto es una escritora de larga y fecunda trayectoria que en los últimos tiempos ha asistido a un reconocimiento de su obra con premios como el de las Letras Valencianas 1992. Dentro del compromi- 
so vital y social que marca su poesía testimonial y solidaria en el medio siglo, se constata una imagen plural de la mujer bien enunciada en el poema «Criatura múltiple» de un libro homónimo de 1954: «iSoy yo tantas mujeres en mí misma! / [...] Yo, múltiple, plural, amigos míos, / no soy nada. Soy todo» (Balcells, 2003: 136-137). Esta pluralidad ya campa en muchos de los poemas de Eva en el tiempo de 1952, así en «La que está en la sombra», «La cansada», «La penitente» o «La peregrina». De igual modo, hay una constante en su poesía, visible en este último poemario, que tiene que ver con la representación de la mujer en dos modelos opuestos que Mónica Jato (2004: 180) distingue con las siguientes palabras: «Se trata, por un lado, de la mujer estática, contemplativa, al pie del hogar y que simboliza la pureza de un ser que no ha sido manchado en el contacto diario con el mundo exterior, y, por otro, la peregrina, la que se hace a sí misma en el dinamismo del camino y que los hombres llaman Eva cuando ésta intenta transmitirles su palabra». El poema «La última mujer» de Eva en el laberinto (Beneyto, 1954: 57-62; recogido en Conde, 1967: 59-62) da cuerpo a ese primer modelo con lo que presenta un sujeto poético femenino que se ajusta a la identidad amparada por la cultura hegemónica.

«La última mujer» aporta una imagen de la identidad femenina que, más allá de pretender un bienestar propio, busca la placidez y el contento de la figura masculina como hombre y como compañero sentimental. Sobresale el dibujo del sujeto poético femenino como una mujer silenciosa («Soy la mujer callada»; «La mujer silenciosa que se desliza leve, / que no pesa, ni invade, ni importuna»), primitiva («esta esperanza mía irracional, de hembra, / mi fe animal y pura y primitiva»), ignorante y ventanera ( «Soy solo una mujer que nada sabe / fuera de ver por la ventana el mundo»), invariable, estática y fiel («Heme aquí»; «La mujer. La de siempre»; «Soy la quieta, la tuya dulcemente»), sencilla («la humildísima»), paridora («Ese redondo ser de las cosechas / humanas, que te acoge y perpetúa»; «yo, génesis que lentamente creo, / [...] y elaboro mis criaturas»; «he gritado al darles [a los hijos] vida»; «La tierra y yo somos mujeres hondas / y bravas paridoras»), guardiana de la casa («La mujer de la casa»), recluida en sus fogones y su cocina («La angosta sombra del fogón remoto»; «Después me iré otra vez a mi cocina»), que no invade ni importuna («la carne dócil, cálida, del lecho»; «Soy intrusa, / solo esta hora de cansancio tuya»). Y frente a ella se erige un sujeto poético masculino definido como varón cansado ( «iEstás ya tan cansado, compañero, / te duele tanto ya la torva herencia!»), con «voz llagada» $\mathrm{y}$ «en el trance amargo», con miedo, agonía y angustia por el devenir oscuro de los tiempos, que no alcanza a valorar la entrega generosa de su pareja. En 
este sentido, María Beneyto actualiza el tópico del ángel del hogar, que enlaza con ese otro tópico del ángel de la retaguardia en los recientes tiempos bélicos y que tiene mucho que ver con un prototipo de mujer educada para ser hacendosa y cándida y ejercer las tareas domésticas con el objetivo preferente de hacer feliz a los demás, esto es, con la imagen nacional-católica de la esposa servicial que actúa de lenitivo para un marido agotado por el trabajo que quiere encontrar un hogar placentero: «yo llevaré el sol hasta tu lecho / como a un animalillo siervo tuyo», concluye el poema de Beneyto.

\section{5. ¡SÍ, LA COCINA! LOS POEMAS DEL HOGAR}

Asimismo, la regla tradicional, fomentada por el franquismo, de reclusión de la mujer en los límites de la casa familiar termina por configurar un sujeto poético con una habitación propia, pero con una suerte de angustia existencial e irrealización personal y una necesidad de volar a través del balcón. El poema de María Beneyto refleja la imagen de esas mujeres ventaneras de las que Martín Gaite hablara en sus ensayos (Desde la ventana) y contara en Entre visillos: «Soy solo una mujer que nada sabe / fuera de ver por la ventana el mundo». A este respecto, la leridana Clemencia Laborda, que se inicia públicamente en la poesía en 1943 con Jardines bajo la lluvia, un poemario garcilasista donde ya se atisban como constantes de su trayectoria la atención a los afectos familiares y una sentida religiosidad, también plantea ese confinamiento de la mujer en «Soledad en la estancia» (recogido en Conde, 1967: 202-206), un poema de 164 versos distribuidos en dieciocho octavas reales, donde retrata a la chica que anhela un amor lejano enclaustrada en su recinto y absorta en un marco de soledad, tristeza, recuerdos y ensueños por un amor ausente. En el comienzo del mismo se lee:

Ahora ya estoy aquí bajo tu cielo, dulcísima provincia de mi casa, nido de sombra donde cierro el vuelo cuando la luz en vuelo me traspasa.

En donde atenta el corazón desvelo y a mis ensueños nunca pongo tasa, aquí donde mis versos improviso a las alturas de un segundo piso (recogido en Conde, 1967: 202).

Lo que pretendo subrayar ahora con la lectura de «Soledad en la estancia» es que la casa produce un doble sentimiento en la mujer. Por un lado, 
la identifica con un «nido de sombra donde cierro el vuelo», es decir, la casa conlleva la clausura, la aflicción, la coerción, el fin del vuelo en libertad y el ingreso en las sombras. Por otro lado, el sujeto poético se refiere a ella como la «dulcísima provincia de mi casa» y, más adelante, la siente como «mi refugio»y «la dulcedumbre en paz de mi aposento». O sea, se nos ofrece una visión paradójica de la misma, ocasionada por la tensión producida entre el apartamiento de la mujer por decisión personal en busca de sosiego y el encierro por dictamen social que hace del hogar un territorio común por el que la mujer vela cuando entra en liza el concepto de familia, tan auspiciado por el franquismo. En este punto, esa estancia familiar termina reduciéndose a la cocina como espacio vital femenino. Como Agustín Serrano de Haro (1946: 123) apunta en La escuela rural al aludir a los estudios de las jóvenes: «Nada de conocimientos científicos para estas niñas. La cocina - isí, la cocina! — debe ser su gran laboratorio» (Pastor, 1984: 32). Así se entiende mejor que la protagonista del poema citado de María Beneyto resuelva: «Después me iré otra vez a mi cocina, / a mis pájaros mudos y a mis sombras».

\section{FINAL}

Valgan estos versos de cierre de una reflexión guiada por la certeza de que el nacional-catolicismo orienta las relaciones del hombre y la mujer en el seno de una doctrina patriarcal, como bien atestiguan las múltiples citas entresacadas de la literatura edificante, religiosa y política, de posguerra. Hay que tener presente que, con independencia de sus afectos o desavenencias con el régimen, las escritoras de la época forman parte de un entramado sociológico y no pueden huir de los condicionantes de un tiempo histórico con unos patrones públicos arraigados en el pasado. Tal tesitura repercute en la producción de numerosas escritoras, cuya poesía refleja a las claras el opresor contexto patriarcal del franquismo y los estereotipos sociales relativos al género que la oficialidad construye y custodia y del que las autoras difícilmente pueden escapar. Los poemas citados en las páginas precedentes ejemplifican el reflejo en la poesía de autoría femenina de los patrones de género impuestos por la ideología y la moral dominantes. Al margen de los que hacen proselitismo abierto del nuevo statu quo, son textos que dan cuenta de la presión social que recae sobre las vidas, actividades y conductas, de las mujeres, es decir, sobre la faceta externa que en síntesis apunta a las labores del ama de casa tradicional, las faenas domésticas y la crianza de los hijos. Pero, a la vez, son textos que transmiten un conflicto esencial en 
sus interioridades. La asunción, avistada en los poemas citados, de las funciones que cultural, ideológica y moralmente se les atribuye no excluye la generación de un estado anímico perturbado que socava su felicidad y su paz interior. Cuando leemos esos poemas de Ester de Andreis, Montserrat Vayreda, Susana March, María Beneyto o Clemencia Laborda se percibe un sentimiento de frustración en los sujetos poéticos femeninos que indica justamente que tienen conciencia del mundo en el que viven y que la sumisión no es ciega. No levantan la voz — como hará, pongamos por caso, una Ángela Figuera en poemas como «Madres», «Destino» o «Mujeres de mercado»-, pero dejan entrever que hay un frente social, moral, económico, jurídico, político, etc. que constriñe sus existencias, que las recluye en las paredes de la casa, que las empuja a la soledad, que las sume en una falta de autoestima y que las invita, casi como única salida, al sueño con una situación colectiva y personal diferente.

\section{REFERENCIAS BIBLIOGRÁFICAS}

ACCIÓN CATÓLICA ESPAÑOLA (1955). Colección de Encíclicas y documentos pontificios. Madrid: Publicaciones de la Junta Técnica Nacional, $5 .^{\mathrm{a}}$ ed. ${ }^{\mathrm{o}}$

ANDREIS, E. (1943). Prímula. Barcelona: Ediciones Mediterráneas.

- (1946). Attimi. Barcelona: [s.e.].

- (1982). Instantes. Barcelona: Juventud.

BALCELLS, J. M. (ed.). (2003). Ilimitada voz (Antología de Poetas Españolas, 1940-2002). Cádiz: Universidad.

BENEYTO, M. (1952). Eva en el tiempo. Valencia: El Sobre Literario.

- (1954). Criatura múltiple. Valencia: Murta.

- (2006). Eva en el laberinto. Valencia: Institució Alfons el Magnànim.

CAVALlO, S. (2006). «Polvo en la tierra: la poesía temprana de Susana March». Arbor 720, julio-agosto, 447-453.

CONDE, C. (ed.) (1954). Poesía femenina española viviente. Madrid: Ediciones Arquero.

-(1967). Poesía femenina española (1939-1950). Barcelona: Bruguera.

DELGADO CAPEANS, R. (1941). La mujer en la vida moderna. Madrid:

Bruno del Amo, 3..$^{\mathrm{a}}$ ed. ${ }^{\circ}$ aumentada.

FUERTES, M. L. (1944). «Mujer y Universidad». Senda 32, marzo. 
GARCÍA FIGAR, A. (1945a). Por qué te casas. Para qué te casas. Con quién te casas. Madrid: Bibliográfica Española.

- (1945b). «¿Decía usted?». Medina 232, 26 de agosto.

GOMÁ Y TOMÁS, I. (1946). La familia según el derecho natural y cristiano. Barcelona: Rafael Casulleras, $5 .^{\mathrm{a}} \mathrm{ed}^{\mathrm{o}}$

GRIMAUD, C. (1942). Futuros esposos. Trad. ${ }^{\circ}$ C. Polo de Álvarez Linera. Madrid: Sociedad de Educación Atenas.

JATO, M. (2004). El lenguaje bíblico en la poesía de los exilios españoles de 1939. Kassel: Edition Reichenberger.

JUANES, J. (1942). «Dolor y gozo de la maternidad». Medina 90, 6 de diciembre.

LABORDA, C. (1943). Jardines bajo la lluvia. Madrid: Talleres Afrodisio Aguado.

MARCH, S. (1938). Rutas. Barcelona: Aviñó.

- (1946). La pasión desvelada. Barcelona: Entregas de Poesía.

- (1953). La tristeza. Madrid: Adonais.

- (1966). Poemas. Antología (1938-1959). Santander: La Isla de los Ratones.

- (1970). Los poemas del hijo. Santander: La Isla de los Ratones.

- (1987). Poemas de la Plaza Real (1939-1945). Sevilla: Colección de Poesía Ángaro.

MARTÍN GAITE, C. (1987a). Usos amorosos de la posguerra española. Barcelona: Anagrama.

- (1987b). Desde la ventana. Enfoque femenino de la literatura española. Madrid: Espasa Calpe.

MARTÍNEZ REDONDO, J. L. (ed.). (1953). Poesía femenina (Antología). Madrid: Estudios.

MILLÁN ASTRAY, P. (1940). Cautivas. 32 meses en las prisiones rojas. Madrid: Saturnino Calleja.

MOLINERO, C. (1999). «Silencio e invisibilidad: la mujer durante el primer franquismo». En Ideología y cultura en la España de los vencedores (1939-1945). Monográfico de Revista de Occidente 223, diciembre, 63-82.

MONTEJO GURRUCHAGA, L. (2006). «La censura de género en la narrativa de autora durante las dos primeras décadas del franquismo». Voz y Letra. Revista de Literatura XVII/2, 107-122. 
MULLOR-HEYMANN, M. (1998). «'General y Señor: Yo te bendigo'. Concha Espina y las escritoras partidarias de Franco». En Vencer no es convencer. Literatura e ideología del fascismo español, M. Albert (ed.), 87-99. Frankfurt am Main-Madrid: Vervuert-Iberoamericana.

PASTOR, M. ${ }^{a}$ I. (1984). La educación femenina en la postguerra (19391945). El caso de Mallorca. Madrid: Ministerio de Cultura / Instituto de la Mujer.

PAYERAS GRAU, M. ${ }^{a}$ (2009). Espejos de palabra. La voz secreta de la mujer en la poesía española de posguerra (1939-1959). Madrid: UNED.

PÍO XII (1951). Boletín Oficial Eclesiástico del Arzobispado de Tarragona, 1 de diciembre.

PRIMO DE RIVERA, P. (1941). «Consigna». Consigna 11, diciembre.

RIDRUEJO, D. (1976). Casi unas memorias. Barcelona: Planeta.

ROCA I GIRONA, J. (1996). De la pureza a la maternidad. La construcción del género femenino en la postguerra española. Madrid: Ministerio de Educación y Cultura.

SERRANO DE HARO, A. (1946). «La escuela rural femenina». En La escuela rural. Madrid: Edit. Escuela Española, 2. ${ }^{\text {e }}$ ed.

SIN AUTOR (1938). «La mujer y el hogar». La mujer de Acción Católica 18 , diciembre.

- (1941a). «Carreras para la mujer». Y 44, setiembre.

- (1941b). «La misión de la mujer». La mujer de Acción Católica 47, octubre.

VAYREDA, M. (1954). «Autoelegía de la mujer estéril». Orfeo 1 (1), 19.

- (1955). Entre el temps i l'eternitat. Barcelona: Altés.

- (2005). Poemes de Montserrat Vayreda (Antologia 1945-2004), A. M. Velaz i Sicart (ed.). Gerona: Diputación Provincial.

VEGA MARTÍNEZ, P. (1988). «El uso de la palabra misión en el lenguaje de la prensa femenina española (1939-1945)». Epos 4, 123-144.

ZECCHI, B. (2002). «Contradicciones del discurso femenino franquista ( $E l$ Ventanal)». En Sexualidad y escritura (1850-2000), R. Medina y B. Zecchi (eds.), 195-212. Barcelona: Anthropos.

Recibido el 24 de mayo de 2013.

Aceptado el 19 de septiembre de 2013. 